\title{
The aging human myocardium: Tolerance to ischemia and responsiveness to ischemic preconditioning
}

Mahmoud Loubani, FRCSI

Sudip Ghosh, FRCS

Manuel Galiñanes, MD, PhD, FRCS
From the Department of Integrative Human Cardiovascular Physiology and Cardiac Surgery, University of Leicester, Glenfield Hospital, Leicester, United Kingdom.

This study was supported by a personal contribution from Professor Manuel Galiñanes.

Received for publication Jan 3, 2002; revisions requested April 30, 2002; revisions received Aug 17, 2002; accepted for publication Aug 22, 2002.

Address for reprints: Professor Manuel Galiñanes, Department of Integrative $\mathrm{Hu}-$ man Cardiovascular Physiology and Cardiac Surgery, University of Leicester, Glenfield Hospital, Leicester LE3 9QP, UK (Email: mg50@le.ac.uk).

J Thorac Cardiovasc Surg 2003;126:143-7

Copyright $(9) 2003$ by The American Association for Thoracic Surgery

$0022-5223 / 2003 \$ 30.00+0$

doi:10.1016/S0022-5223(02)73601-5
Background: Increasing age has been recognized as a cause for adverse prognosis in the setting of myocardial infarction, coronary angioplasty, and cardiac surgery. This is attributed to a greater susceptibility of the senescent heart to ischemic injury and to a lower response to protective interventions. This study investigated the effect of aging on the tolerance to ischemia of the human myocardium and its response to ischemic preconditioning.

Methods: Right atrial specimens from 128 patients undergoing elective heart surgery were collected, sliced, and equilibrated for 30 minutes before being randomized into 3 study protocols: (1) 210 minutes of aerobic incubation (time-matched control), (2) 90 minutes of simulated ischemia and 120 minutes of reoxygenation, and (3) ischemic preconditioning with 5 minutes of ischemia and 5 minutes of reoxygenation before 90 minutes of ischemia and 120 minutes of reoxygenation. Patients were subdivided into 3 age groups: 30 to 49 years, 50 to 69 years, and 70 to 90 years. At the end of each protocol, tissue injury and viability were assessed by the leakage of creatine kinase and the reduction of 3-(4,5 dimethylthiazol-2-yl)-2,5 diphenyltetrazolium bromide to insoluble formazan dye.

Results: There were no differences among the 3 groups of patients in their comorbid conditions or their cardiac medications. Ischemic injury was similar in all 3 groups (creatine kinase $=4.1 \pm 0.7,3.6 \pm 1.0$, and $4.3 \pm 1.1 \mathrm{U} / \mathrm{g}$ wet weight, respectively; 3-(4,5 dimethylthiazol-2-yl)-2,5 diphenyltetrazolium bromide $=64.7 \pm 31.3,96.3$ \pm 32.0 , and $61.0 \pm 30.4 \mathrm{mM} / \mathrm{g}$ wet weight, respectively, $P=$ not significant in all cases), and ischemic preconditioning equally protected against ischemia at all ages (creatine kinase $=1.9 \pm 0.5,1.8 \pm 0.4$, and $2.1 \pm 0.6 \mathrm{U} / \mathrm{g}$ wet weight, respectively; 3-(4,5 dimethylthiazol-2-yl)-2,5 diphenyltetrazolium bromide $=157.9 \pm 31.5$, $170.7 \pm 35.3$, and $138.4 \pm 43.8 \mathrm{mM} / \mathrm{g}$ wet weight, respectively; $P<.05$ in all cases vs ischemia alone).

Conclusion: Age does not influence the tolerance of the human myocardium to ischemia or the protective effect of ischemic preconditioning. These results indicate the need for a reevaluation of the importance of age in risk scoring in cardiac surgery.

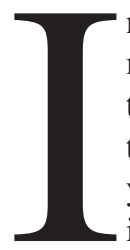
ncreasing age has been recognized as a cause for adverse prognosis in myocardial infarction, ${ }^{1,2}$ coronary angioplasty, ${ }^{3}$ and cardiac surgery. ${ }^{4,5}$ This thesis is supported by animal ${ }^{6}$ and human ${ }^{7}$ in vitro studies suggesting that the aged myocardium is more susceptible to ischemic injury than is the young myocardium. However, Ivanov and colleagues ${ }^{5}$ recently reported an improvement in operative mortality during heart surgery in the past 2 decades despite an increase in the prevalence of elderly patients and the greater severity of their risk factors, which indicates that the associated comorbid conditions, not age per se, are the main detrimental factors. The undefined role of age as a risk factor during cardiac surgery is also reflected by the differences in the risk 
scoring systems of Parsonnet ${ }^{8}$ and the European System for Cardiac Operative Risk Evaluation (EuroSCORE). ${ }^{9}$

It is also unclear whether the protection obtained with interventions such as ischemic preconditioning is altered in the aging heart. Ischemic preconditioning with brief periods of ischemia has been demonstrated to protect both animal $^{10,11}$ and human ${ }^{12,13}$ myocardium from a subsequent ischemic insult. This has been demonstrated in aged rabbit ${ }^{14}$ and sheep ${ }^{15}$ hearts, but it has been questioned in the aged myocardium of rat heart. ${ }^{16,17}$

This study determines the effect of age on the tolerance of the human myocardium to ischemia and investigates whether age affects the protection afforded by ischemic preconditioning.

\section{Methods}

\section{Experimental Preparation}

Experiments were performed on myocardium obtained from the right atrial appendage of 128 patients undergoing elective coronary artery surgery or aortic valve replacement in an in vitro model that was developed in our laboratory and described previously. ${ }^{18} \mathrm{~Pa}-$ tients were excluded if they had enlarged atriums, atrial arrhythmias, poor left ventricular function (ejection fractions $<30 \%$ ), right ventricular failure, or diabetes mellitus or were taking oral hypoglycemic agents, opioid analgesia, $\mathrm{K}_{\mathrm{ATP}}$ channel openers, or catecholamines. All other medications were discontinued 1 day before surgery. Local ethical committee approval was obtained for the harvesting technique. The specimens were collected in oxygenated HEPES buffered solution at $4^{\circ} \mathrm{C}$ to $5^{\circ} \mathrm{C}$ and immediately sectioned and prepared for study. Briefly, the appendage was mounted onto a ground glass plate with the epicardial surface face down and then sliced freehand with use of surgical skin graft blades (Swann-Morton, Sheffield, UK) to a thickness of between 300 and $500 \mu \mathrm{m}$. The muscles (weight $30-50 \mathrm{mg}$ ) were then transferred to conical flasks $(25 \mathrm{~mL}$ Erlenmeyer flasks Schott Glaswerk, Mainz, Germany) containing $10 \mathrm{~mL}$ of oxygenated buffered solution, and the flasks were placed in a shaking water bath maintained at $37^{\circ} \mathrm{C}$. The oxygenation of the incubation medium was maintained by a continuous flow of $95 \% \mathrm{O}_{2} / 5 \% \mathrm{CO}_{2}$ gas mixture to obtain a $\mathrm{PO}_{2}$ between 185 and $225 \mathrm{~mm} \mathrm{Hg}$ and a $\mathrm{PCO}_{2}$ between 45 and $50 \mathrm{~mm} \mathrm{Hg}$. The $\mathrm{Po}_{2}, \mathrm{PCO}_{2}$, and $\mathrm{pH}$ in the incubation medium were monitored by intermittent analyses of the effluent by using an automated blood gas analyzer (model 855 Blood Gas System, Chiron Diagnostics, Halstead, United Kingdom), and the $\mathrm{pH}$ was kept between 7.36 and 7.45. For the induction of simulated ischemia, the medium was bubbled with $95 \% \mathrm{~N}_{2} / 5 \% \mathrm{CO}_{2}(\mathrm{pH}$ 6.80-7.00) and D-glucose replaced with 2-deoxyglucose. The incubation media was bubbled with $95 \%$ $\mathrm{N}_{2} / 5 \% \mathrm{CO}_{2}$ for 20 minutes before the induction of simulated ischemia or ischemic preconditioning. Previous studies in our laboratory have demonstrated that the $\mathrm{O}_{2}$ was $0 \mathrm{Kpa}$ within 2 minutes of the initiation of bubbling. The atrial tissue was not paced, and the force developed was not measured in these studies.

\section{Solutions}

The incubation medium was prepared daily with deionized distilled water and contained (in millimoles per liter) $\mathrm{NaCl}_{2}$ (118),
$\mathrm{KCl}$ (4.8), $\mathrm{NaHCO}_{3}$ (27.2), $\mathrm{MgCl}_{2}$ (1.2), $\mathrm{KH}_{2} \mathrm{PO}_{4}$ (1.0), $\mathrm{CaCl}_{2}$ (1.25), D-glucose (10), and HEPES (20). As mentioned previously, D-glucose was substituted with 2-deoxyglucose $(10 \mathrm{mmol} / \mathrm{L})$ during simulated ischemia to maintain a constant osmolarity.

\section{Experimental Protocol}

After the atrium was sectioned, the preparations were allowed to stabilize for 30 minutes and then randomly allocated to one of the following groups: (1) aerobic perfusion for 210 minutes, to serve as aerobic time-matched controls, (2) simulated ischemia for a period of 90 minutes followed by 120 minutes of reoxygenation, and (3) ischemic preconditioning induced by 5 minutes of ischemia and 5 minutes of reoxygenation immediately before the 90 minutes of ischemia-a protocol shown to afford maximal protection in this preparation. ${ }^{19}$ Patients were divided into 3 different groups according to age (30-49 years $[\mathrm{n}=18], 50-69$ years $[\mathrm{n}=$ 66], and 70-90 years $[\mathrm{n}=44]$ ) to allow comparison between the different age groups.

\section{Assessment of Tissue Injury and Viability}

Tissue injury was determined by measuring the leakage of creatine kinase (CK) into the incubation medium during the 120-minute reoxygenation period. This was assayed by a kinetic ultraviolet method based on the formation of nicotinamide adenine dinucleotide (No. 1340-K, Sigma, St Louis, Mo), and the results were expressed as units per gram wet weight.

Tissue viability was assessed by the reduction of 3-(4,5 dimethylthiazol-2-yl)-2,5 diphenyltetrazolium bromide (MTT) to a blue formazan product at the end of the experimental time. The tissue was loaded into a Falcon conical tube $(15 \mathrm{~mL}$, Becton Dickinson Labware, Franklin Lakes, NJ) into which 2 $\mathrm{mL}$ of phosphate buffer solution $(0.05 \mathrm{~mol} / \mathrm{L})$, containing MTT $(1.25 \mathrm{mg} / \mathrm{mL}, 3 \mathrm{mmol} / \mathrm{L}$ at final concentration), was added and then incubated for 30 minutes at $37^{\circ} \mathrm{C}$. After this, the tissue was homogenized in $2 \mathrm{~mL}$ of dimethyl sulfoxide (Homogenizer Ultra-Turrax T25, dispersing tool G8, IKA-Labortechnic, Staufen, Germany) at $9500 \mathrm{rpm}$ for 1 minute. The homogenate was then centrifuged at $1000 \mathrm{~g}$ for 10 minutes, and $0.2 \mathrm{~mL}$ of the supernatant was dispensed into a 98-well flat-bottom microtiter plate (Nunc Brand Products, Roskilde, Denmark). After this, the absorbance of the blue formazan formed was measured on a plate reader (Benchmark, Bio-Rad Laboratories, Hercules, Calif) at $550 \mathrm{~nm}$, and the results were expressed as millimoles per gram wet weight.

\section{Statistical Analysis}

All data are presented as mean \pm standard deviation. Analysis of variance was used for multiple comparisons with the application of the Tukey post hoc test. Linear regression analysis was used when appropriate.

\section{Results}

The demographic data, the risk factors, and the medical treatment were similar in the 3 age groups (see Table 1). Figure 1 shows that simulated ischemia and reoxygen- 

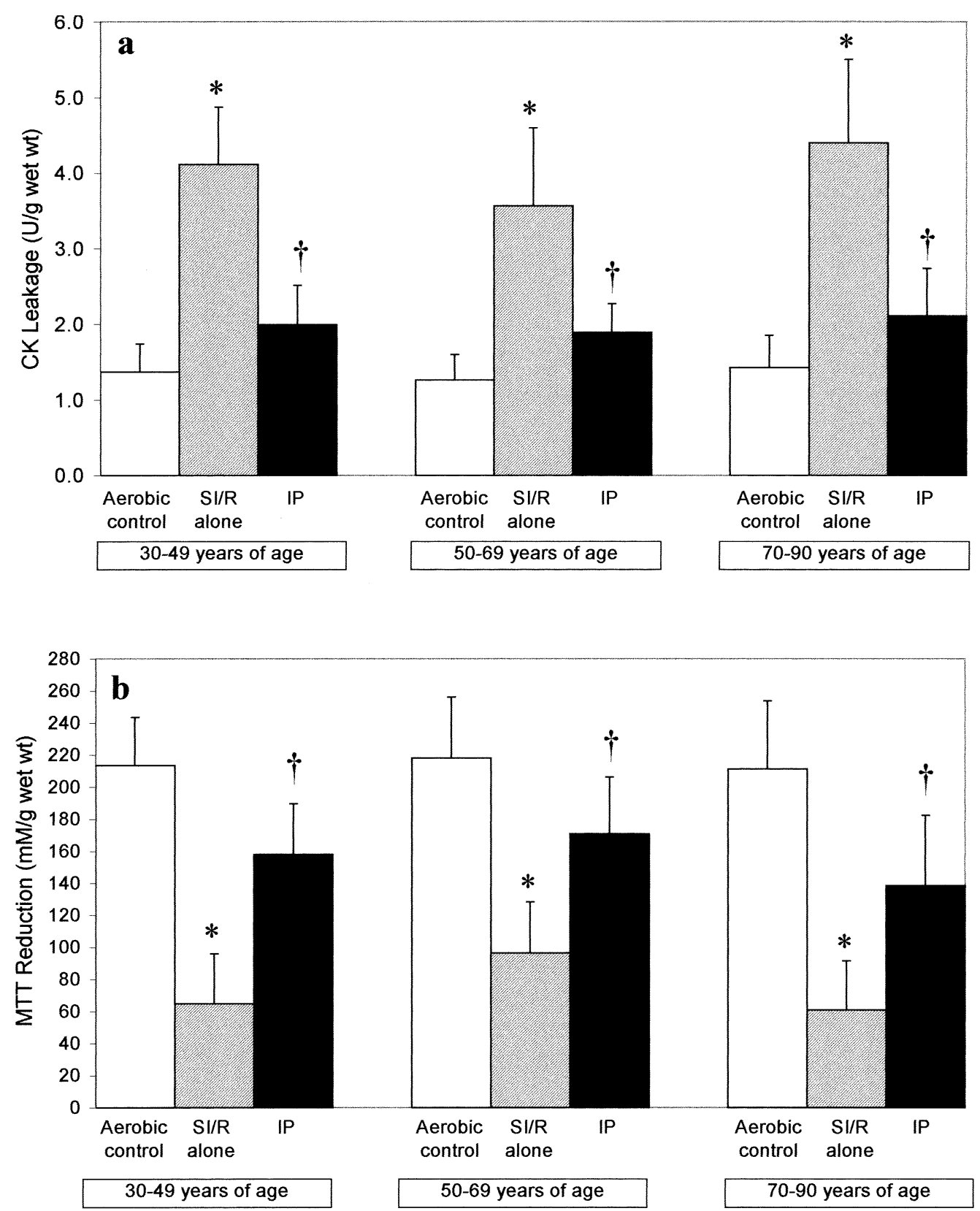

Figure 1. Creatine kinase (СК) leakage into the media (a) during the 120 -minute reoxygenation period and $3-(4,5$ dimethylthiazol-2-yl)-2,5 diphenyltetrazolium bromide (MTT) reduction by the slices (b) at the end of the reoxygenation period in the human atrial myocardium from the different age groups subjected to 90 minutes of simulated ischemia and 120 minutes of reoxygenation preceded or not by ischemic preconditioning. Data are expressed as mean \pm standard deviation of the patients in each group (30-49 years of age $[n=18], 50-69$ years of age [ $n=66$ ] and $70-90$ years of age $[n=44] ; * P<.05$ versus aerobic control group; $t P<.05$ versus simulated ischemia and reoxygenation alone group).

ation resulted in significant increases in CK leakage and decreases in MTT reduction that were similar in all 3 age groups. They also show that ischemic preconditioning afforded similar protection in all age groups. Linear regression analyses clearly demonstrated that the degree of ischemic injury and the protection obtained with ischemic preconditioning does not change with increasing age $\left(\mathrm{R}^{2}=0.0051,10^{-4}\right.$, and 0.0178 for $\mathrm{CK}$ leakage and $\mathrm{R}^{2}=0.0216,4 \times 10^{-5}$, and 0.0295 for MTT reduction for aerobic control, simulated ischemia, and reoxygen- 
TABLE 1. Patients' demographic data and medical treatment

\begin{tabular}{|c|c|c|c|}
\hline & $\begin{array}{l}\text { Group } 1 \\
(30-49 \mathrm{yr})\end{array}$ & $\begin{array}{l}\text { Group } 2 \\
(50-69 \mathrm{yr})\end{array}$ & $\begin{array}{l}\text { Group } 3 \\
(70-90 \mathrm{yr})\end{array}$ \\
\hline Number of patients & 18 & 66 & 44 \\
\hline Sex (male:female) & $12: 6$ & $39: 27$ & 28:16 \\
\hline Hypertension & $8(44 \%)$ & $31(46 \%)$ & $22(52 \%)$ \\
\hline Hypercholesterolemia & $12(66 \%)$ & $39(59 \%)$ & $28(63 \%)$ \\
\hline Cerebrovascular accident & $1(5 \%)$ & $4(6 \%)$ & $5(11 \%)$ \\
\hline $\begin{array}{l}\text { Peripheral vascular disease } \\
\text { Medications }\end{array}$ & $1(5 \%)$ & $8(12 \%)$ & $6(14 \%)$ \\
\hline Nitrates & 14 (78\%) & $50(76 \%)$ & $35(80 \%)$ \\
\hline Diuretics & $6(33 \%)$ & $21(32 \%)$ & $15(34 \%)$ \\
\hline Ca channel antagonists & $13(72 \%)$ & $41(62 \%)$ & $25(56 \%)$ \\
\hline$\beta$-blockers & $12(66 \%)$ & $39(59 \%)$ & $21(48 \%)$ \\
\hline ACE inhibitors & $11(61 \%)$ & $31(47 \%)$ & $20(45 \%)$ \\
\hline
\end{tabular}

$A C E$, Angiotensin-converting enzyme.

ation alone, and ischemic preconditioning in all patients, respectively).

\section{Discussion}

This study is the first to report that the necrosis induced by a severe ischemic insult of human atrial myocardium is not exacerbated by increasing age, and that ischemic preconditioning equally protects the myocardium of all ages as assessed by CK leakage and MTT reduction. These findings have important clinical implications regarding the selection and treatment of patients presenting with ischemic syndromes and warrant further discussion.

Ischemia occurs in a number of clinical settings that include myocardial infarction, coronary angioplasty, and cardiac surgery. Ischemic heart syndromes are the most common cause of death in elderly patients, ${ }^{1,2}$ and it has been suggested that a greater vulnerability to ischemic injury of this age group is a major contributor. ${ }^{1-4}$ This thesis finds support in experimental studies showing that a greater calcium overload ${ }^{20}$ and increased oxygen free-radical generation $^{21}$ occur in the senescent rat heart and that hearts become less tolerant to ischemia with age. ${ }^{6}$ However, the results from this study show that the degree of ischemic injury in the human myocardium does not seem to be related to age. The controversy is further fueled by the results recently reported by Mariani and colleagues ${ }^{7}$ showing that aged human atrial myocardium (also obtained from patients undergoing cardiac surgery) has a reduced capacity to recover developed force after hypoxia or simulated ischemia than younger myocardium, although contraction duration, time to peak tension, and time to $50 \%$ relaxation were unaffected by age. Therefore, the results of the study by Mariani and colleagues ${ }^{7}$ may be subject to different interpretations depending on the parameter examined. In trying to reconcile these results, it is possible that preconditioning by ischemia can take many forms, and that some protection may be lost with age, whereas other forms are retained. Indeed, the confirmation of this hypothesis requires further investigation.

Ischemic injury as measured by the 2 parameters used in our study was unaffected by age. Thus, the use of age as a risk factor in mortality and morbidity after myocardial infarction, ${ }^{1,2}$ in patients undergoing coronary angioplasty, ${ }^{3}$ or during cardiac surgery ${ }^{4,5}$ may be questionable. This may indicate that the greater incidence of comorbidities in elderly patients is more important for risk stratification than age per se. Therefore, in light of the present results, therapeutic interventions such as cardiac surgery should not be decided on the basis of age alone, and they prompt us to reevaluate the impact of age in the risk scoring systems of Parsonnet $^{8}$ and EuroSCORE. ${ }^{9}$

The second major finding of the present study is that the protection of the human atrial myocardium by ischemic preconditioning against ischemic necrosis is not influenced by age. This contrasts with the findings of Abete and colleagues ${ }^{17}$ showing that the senescent rat heart cannot be preconditioned with ischemia. However, despite these results, these investigators also showed that both adult and senescent hearts can be equally pharmacologically preconditioned with exogenous norepinephrine, indicating that the preconditioning signal transduction pathway is preserved in both age groups. This is further supported by reports from McCully and colleagues ${ }^{14}$ and Burns and colleagues ${ }^{15}$ demonstrating the ability to precondition the senescent hearts of rabbits and sheep. The mechanism of ischemic and pharmacologic preconditioning is the object of intense investigation and not fully understood; however, Tani and colleagues ${ }^{16}$ observed differences in the translocation of protein kinase $\mathrm{C}$ between young and middle-aged rats that demonstrates the possibility of distinct characteristics in the signaling pathway of preconditioning in different age groups. The elucidation of this pathway will be invaluable to exploit the protective action of preconditioning and to combat ischemic injury. The use and refinement of preconditioning will help to improve the prognosis and outcome of the sufferers of ischemic heart disease in the elderly population and will make procedures such as coronary angioplasty and cardiac surgery safer.

A potential limitation of the present study is that the investigation was performed using human atrial tissue instead of ventricular myocardium; therefore, any extrapolation to the latter should be performed with caution. Speechly-Dick, Grover, and Yellon, however, have suggested that preconditioning exerts identical protection in both tissues. ${ }^{12}$ Another possible limitation is that we used an in vitro model, and extrapolation of this to the clinical setting should also be performed with caution. Finally, it should be clarified that the results obtained in the present study may not be extended to other degrees of tissue injury 
and to the effect on contractile function or electrophysiologic properties of the tissue.

\section{References}

1. Harris R, Pirqacha AR. Acute myocardial infarction in the aged: prognosis and management. J Am Geriatr Soc. 1970;18:893-904.

2. Latting CA, Silverman ME. Acute myocardial infarction in hospitalised patients over age 70. Am Heart J. 1980;100:311-8.

3. Wenberg DE, Makenka DJ, Sengupta A, et al. Percutaneous transluminal angioplasty in the elderly: epidemiology, clinical risk factors, and in-hospital outcomes. Am Heart J. 1999;137:639-45.

4. Tu JV, Jaglal SB, Naylor CD. Multicenter validation of a risk index for mortality, intensive care unit stay, and overall hospital length of stay after cardiac surgery. Circulation. 1995;91:677-84.

5. Ivanov J, Weisel RD, David TE, et al. Fifteen-year trends in risk severity and operative mortality in elderly patients undergoing coronary artery bypass graft surgery. Circulation. 1998;97:673-80.

6. Tani M, Suganuma Y, Hasegawa $\mathrm{H}$, et al. Changes in ischemic tolerance and effects of ischemic preconditioning in middle-aged rat hearts. Circulation. 1997;95:2559-66.

7. Mariani J, Ou R, Bailey M, et al. Tolerance to ischemia and hypoxia is reduced in aged human myocardium. J Thorac Cardiovasc Surg. 2000;120:660-7.

8. Parsonnet V, Dean D, Bernstein AD. A method of uniform stratification of risk for evaluating the results of surgery in acquired heart disease. Circulation. 1989;79(suppl I):I-3-12.

9. Roques F, Nashef SAM, Michel P, et al. Risk factors and outcome in European cardiac surgery: analysis of the EuroSCORE multinational database of 19030 patients. Eur J Cardiothorac Surg. 1999;15:816-23.

10. Murry CE, Sennings RB, Reimer KA. Preconditioning with ischemia: a delay of lethal cell injury in ischemic myocardium. Circulation. 1986;74:1124-36.
11. Mitchell MB, Meng X, Ao L, et al. Preconditioning of isolated rat heart is mediated by protein kinase C. Circ Res. 1995;76:73-81.

12. Speechly-Dick ME, Grover GJ, Yellon DM. Does ischemic preconditioning in the human involve PKC and the ATP-dependent $\mathrm{K}^{+}$channel. Circ Res. 1995;77:1030-5.

13. Cleveland JC Jr, Wollmering MM, Meldrum DR, et al. Ischemic preconditioning in human and rat ventricle. Am J Physiol. 1996;271: H1786-94.

14. McCully JD, Uematsu M, Parker RA, et al. Adenosine-enhanced ischemic preconditioning provides enhanced cardioprotection in the aged heart. Ann Thorac Surg. 1998;66:2037-43.

15. Burns PG, Krunkenkamp IB, Calderone CA, et al. Is the preconditioning response conserved in senescent myocardium. Ann Thorac Surg. 1996;61:925-9.

16. Tani M, Honma Y, Hasegawa H, et al. Direct activation of mitochondrial KATP channels mimics preconditioning but protein kinase $\mathrm{C}$ activation is less effective in middle-aged rat hearts. Cardiovasc Res. 2001;49:56-68.

17. Abete P, Ferrara N, Cioppa A, et al. Preconditioning does not prevent postischaemic dysfunction in ageing heart. J Am Coll Cardiol. 1996; 27:1777-86.

18. Zhang JG, Ghosh S, Ockelford C, et al. Characterization of an in vitro model for the study of the short and prolonged effects of myocardial ischaemia and reperfusion in man. Clin Sci. 2000;99:339-50.

19. Ghosh S, Standen NB, Galiñanes M. Preconditioning the human myocardium by simulated ischemia: studies on the early and delayed protection. Cardiovasc Res. 2000;45:339-50.

20. Ataka K, Chen D, Levitsky S, et al. Effect of ageing on intracellular $\mathrm{Ca} 2+, \mathrm{pH}$ and contractility during ischemia and reperfusion. Circulation. 1992;86(suppl II):II-371-6.

21. Cortopassi GA, Wong A. Mitochondria in organismal ageing and degeneration. Biochem Biophys Acta. 1999;1410:183-93.

\section{Online-www.aats.org}

Now you can get The Journal of Thoracic and Cardiovascular Surgery online. The Journal online brings you faster delivery time, easy searching of current and back issues, links to PubMed, AATS, WTSA, and other important sites, and more. Visit the Journal online today.

\section{Receive tables of contents by e-mail}

To receive the tables of contents by e-mail, sign up through our Web site at http://www.mosby.com/jtcvs

Choose $E$-mail Notification

Simply type your e-mail address in the box and click the Subscribe button.

Alternatively, you may send an e-mail message to majordomo@mosby.com.

Leave the subject line blank and type the following as the body of your message: subscribe jtcvs_toc

You will receive an e-mail to confirm that you have been added to the mailing list.

Note that TOC e-mails will be sent out when a new issue is posted to the Web site. 